\title{
As gurias do Sul: representações das jovens gaúchas em ar- tefatos culturais midiáticos impressos
}

\author{
Girls from the South of Brazil: \\ representations of the young girls from \\ Rio Grande do Sul in cultural media \\ printed artifacts
}

Rossana Cassanta ROSSI*

Resumo: Minha intenção, no presente artigo, é analisar as representações de jovens gaúchas em determinados artefatos culturais midiáticos impressos, os quais podem ser interpelativos, podem governar e subjetivar os sujeitos. Essa análise é realizada na perspectiva dos Estudos Culturais, que consideram a cultura como um dos principais lócus onde são estabelecidas e, ao mesmo tempo, contestadas divisões desiguais próprias das sociedades capitalistas industriais, como as divisões de gerações, de classes, de etnias e de sexo. Nesse campo de estudos, os mencionados artefatos podem ser vistos como uma forma de pedagogia cultural que, no caso da leitura realizada, aponta para o fato de que não se deve ignorar a possibilidade de muitas jovens, inclusive as de nossas escolas, estarem continuamente expostas e, possivelmente, governadas por tais discursos midiáticos. Mostra, também, que é importante desconfiar desses discursos subjetivadores, os quais, ao representar ou narrar, ensinam as jovens a agir e a ser como mostram as representações que delas fazem. Logo, continuar a problematizar olhares produzidos nas culturas pode ser um dos caminhos necessários para compreender os significados de tais representações, a fim de se possa desnaturalizar aquilo que é aceito como verdade.

Palavras-chave: estudos culturais. juventude. gênero. artefatos culturais midiáticos.

Abstract: In the perspective of Cultural Studies, I analyze the representations of the young girls from Rio Grande do Sul in cultural media printed artifacts (newspapers and magazine), which are understood as a form of cultural pedagogy, which can be interpellative, can govern subjects. Therefore, considering that youth has been one of

\footnotetext{
* Graduada em Letras pela Universidade Federal de Santa Maria. E-mail: sanarossi@yahoo.com.br
}

Olhar de professor, Ponta Grossa, 9(1):119-130, 2006. 
the great thematic used by media, it is important to distrust of these discourses that subject, teach to young girls to be as they (newspapers and magazine) say that they (girls) are.

Keywords: cultural studies. youth. gender. cultural media artifacts.

Neste artigo, inscrito em uma perspectiva pós-moderna, minha pretensão é fazer uma leitura sobre as representações das jovens gurias ${ }^{1}$ em determinados artefatos culturais midiáticos impressos, como jornais e revistas, por exemplo. A importância de olhar para essas questões nos Estudos Culturais é ressaltada por Costa (2000a, p. 25):

Os Estudos Culturais reconhecem as sociedades capitalistas industriais como lugares de divisões desiguais no que se refere a etnia, sexo, divisões de gerações e de classes. A cultura é um dos principais lócus onde são estabelecidas e contestadas tais divisões, onde se dá a luta pela significação, na qual os grupos subordinados tentam resistir à imposição de significados que sustentam os interesses dos grupos dominantes. Neste sentido, os textos culturais são muito importantes, pois eles são um produto social, o local onde o significado é negociado e fixado.

Além disso, "a cultura é vista como uma pedagogia, a pedagogia é vista como uma forma cultural: o cultural torna-se pedagógico, e a pedagogia torna-se cultural" (SILVA, 2004). Entendo por pedagogia cultural "qualquer instituição ou dispositivo cultu- ral que, tal como a escola, esteja envolvido [...] no processo de transmissão de atitudes e valores, tais como o cinema, a televisão, as revistas, os museus, etc" (SILVA, 2000, p. 89).

Minha intenção, baseada em Veiga-Neto, é expor uma "nova maneira de ver o mundo e com ele nos relacionarmos, nem melhor nem pior do que outras, nem mais correta nem mais incorreta do que outras" (VEIGANETO, 2002, p. 34). Para o pensamento pós-moderno não há uma posição privilegiada, não há uma única verdade sobre o mundo. No pós-moderno, tem-se "o abandono da esperança de haver um lugar privilegiado a partir do qual se possa olhar e compreender definitivamente as relações, que circulam no mundo" (idem, 35).

\section{O SUJEITO E AS IDENTIDADES PÓS-MODERNAS}

Ao romper com as metanarrativas, pressupostos sobre os quais se assenta a modernidade, rompe-se também com as metanarrativas do sujeito moderno, um sujeito unificado, centrado, dotado das capacidades de razão, como descreve Hall (1998).

\footnotetext{
1 'Guria' é uma expressão da cultura gaúcha, utilizada para se referir à 'garota', 'jovem',
} 'menina', 'moça', etc. 
Desse modo, para Veiga-Netto (2000, p. 51),

o pensamento pós-moderno opera o descentramento do sujeito, ou seja, remove do centro dos processos sociais - e, conseqüentemente, das análises que se fazem desses processos o sujeito ali colocado pelas filosofias da consciência. Com isso, elide-se o sujeito transcendental, que passa a ser visto como uma invenção iluminista e não como uma sua descoberta.

Hall (1998) expõe que o sujeito pós-moderno é um sujeito definido historicamente, de identidade fragmentada, composto de várias identidades, as quais algumas vezes podem ser contraditórias ou não-resolvidas. Também se caracteriza por assumir identidades diferentes, em diferentes momentos. Acrescenta, ainda, que devemos pensar as identidades sociais como construídas no interior da representação, através da cultura, não fora dela. Elas são o resultado de um processo de identificação que permite que nos posicionemos no interior das definições que os discursos culturais (exteriores) fornecem, ou que nos subjetivemos (dentro deles) (HALL, 1997). De acordo com o autor,

a identidade emerge, portanto, não tanto de um centro interior, de um "eu verdadeiro e único", mas do diálogo entre os conceitos e definições que são representados para nós pelos discursos de uma cultura e pelo nosso desejo (consciente ou inconsciente) de responder aos apelos feitos por estes significados, de sermos interpelados por eles, de assumirmos as posições de sujeito construídas para nós por alguns dos discursos para nos identificarmos. Nossas identidades são, em resumo, formadas culturalmente.

\section{ARTEFATOS CULTURAIS MIIDIÁTICOS IMPRESSOS}

Artefatos culturais são textos, imagens, filmes, músicas, entre outros; são "sistemas de significação implicados na produção de identidades e subjetividades, no contexto de relações de poder" (SILVA, 2004, p. 142). A importância de se analisar artefatos culturais é destacada por Costa (2000b), que afirma que eles são interpelativos e nos instigam a ser da forma como dizem que somos. Dessa forma, nos capturam e nos tornam governáveis, produzindo assim uma forma de sujeição, de subjetivação. A autora também declara que "as identidades, dentre tantas que são compostas, expressam sujeitos produzidos por discursos subjetivadores que operam estratégias representacionais inscritas nas lógicas e interesses políticos de seu tempo".

Além disso, não se deve negligenciar o caráter pedagógico da mídia presente nesses artefatos. Kellner (1995), ao fazer um estudo sobre as imagens publicitárias, enfatiza a necessidade de se adquirir um alfabetismo crítico em relação à mídia para "fortalecer o poder dos indivíduos, ao capacitá-los para aprender a ver através das mistificações de seu ambiente, a ver como ele é construído e como 
funciona e a ver como eles podem se libertar dos aspectos dominantes e opressivos e aprender a refazer a sociedade como uma modalidade do eu e da atividade social" (idem, p. 127).

Para analisar algumas das representações das jovens gaúchas em artefatos impressos, selecionei textos da revista Veja (de circulação nacional), do suplemento Donna do jornal Zero Hora, notícias do Correio do Povo, (jornais de circulação no Estado do Rio Grande do Sul), textos de $A$ Razão (um jornal local, da cidade de Santa Maria/RS). Nesses textos, encontrei representações sobre jovens no espaço da tradição gaúcha, no esporte e na moda.

\section{AS JOVENS DO RIO GRANDE DO SUL - ENTRE PRENDAS, DESPORTISTAS E MODELOS}

A temática da juventude tem sido uma das grandes investidas da mídia. Inúmeras propagandas têm abordado o desejo de ser jovem, de tornar-se jovem. Um exemplo disso são as propagandas das indústrias de cosméticos. É comum vermos imagens de mulheres na faixa etária de 35-55 anos com uma aparência mais jovem, associada ao produto anunciado. Além disso, elas sempre aparecem sorridentes, felizes, numa referência ao discurso que asso- cia juventude e felicidade.

Reguillo (2003, p. 23) afirma que “os jovens não representam um categoria unívoca. A juventude é uma categoria construída culturalmente, não se trata de uma essência"2. Já Sarlo (1997, p. 39), em seu estudo sobre as cenas da vida pós-moderna, argumenta que "a juventude é um território onde todos querem viver indefinidamente". Contudo, faz uma advertência, dizendo que "o impulso igualitário que às vezes se crê encontrar na cultura dos jovens tem seus limites nos preconceitos sociais e raciais, sexuais e morais" (idem, p. 42).

\section{SOBRE AS PRENDAS ${ }^{3}$...}

Uma das representações que podemos encontrar nos materiais selecionados está relacionada com a tradição gaúcha: ser prenda. Na matéria "Mulher de tradição", de Rocha (2002), a prenda é representada como uma mulher recatada, comportada, submissa, que possui estudo (conhecimento sobre sua cultura) e que tem o papel de educar, de ser esposa e mãe.

Segundo o texto, "o recato do passado e a independência dos dias de hoje convivem nos hábitos das prendas do século 21" (ROCHA,2002, p. 05). Essa primeira questão é observada através (a) da vestimenta, uma

\footnotetext{
${ }^{2}$ A tradução de Reguillo é de responsabilidade da autora.

${ }^{3}$ Simplificadamente, 'prenda' é um termo usado na tradição gaúcha para se fazer referência às mulheres; já a palavra 'peão' é empregada como referência aos homens.
} 
vez que "ao vestir, a pilcha, elas reverenciam as mulheres das estâncias, que serviam o marido e as visitas, mas não se sentavam para comer" (ibidem); e (b) do comportamento, pois "o MTG ensina às prendas a postura discreta, que inclui regras como não fumar, beber ou 'ficar' em público"(ibidem). Walkerdine (1995), ao fazer uma análise sobre o gênero feminino, constata essas mesmas características em seu estudo: "as garotas eram acusadas de ir bem [na escola] porque trabalhavam muito, seguiam regras, comportavam-se bem. Indicadores disso eram sua atitude de obediência e o comportamento na sala de aula" (idem, p. 214). Ainda, uma das prendas entrevistadas afirma que $a$ "mulher é respeitada no CTG, e ser prenda me faz feliz. Somos pessoas normais". O respeito parece, desse modo, uma forma de recompensa pelo bom comportamento das prendas.

O tema da submissão confrontase com o da independência, sugerindo, desse modo, um aspecto contraditório na cultura gaúcha. Essa primeira característica, presente no passado da cultura, está relacionada com o machismo e ambas são confirmadas através do termo prenda. Segundo um folclorista entrevistado nessa matéria, "Mulher de Tradição", "o termo prenda, a rigor, é machista. Significa que me pertence. Mas é como eles eram naquele tempo, machistas. Hoje, se tentar controlar essas mulheres, elas corcoveiam". Porém, a atitude machista não parece ter sido total- mente superada na visão de uma das entrevistas, já que ela foi reeleita três vezes patroa do CTG, mas como o marido ganha o título de patrão por tabela, seu cargo nem sempre é respeitado porque "na reunião de patrões, se dirigem a meu marido, mesmo sabendo que eu farei as coisas", diz ela. Tentando romper com esses discursos, uma das jovens entrevistadas diz: "Não vou deixar de ter meu emprego porque no passado as mulheres eram sustentadas pelos maridos. A prenda é moderna e precisa ter suas responsabilidades".

Esses temas também são problematizados em relação ao vestuário da prenda. Ao mostrar diversas reportagens sobre a comemoração da Semana Farroupilha de 2001, o jornal Correio do Povo apresenta o texto "Carazinho boicota prendas de chiripá", segundo o qual as prendas vestidas de chiripá foram impedidas de participarem do desfile em comemoração à Revolução Farroupilha. Ao ser entrevistado, o coordenador da Semana Farroupilha da cidade explica que "o chiripá é exclusivo de uso masculino. Não devemos confundir o belo visual das prendas e mulheres gaúchas com nossa indumentária de usos e costumes". Ao lado desse texto, há um outro, "Momento para reafirmar valores", no qual o governador do estado na época, ao ser entrevistado, diz:

O Rio Grande do Sul vive um momento maravilhoso de reafirmação dos valores que nunca envelhecem e que 
estão gravados na memória, no coração e na consciência do povo gaúcho. É um sentimento que está gravado na nossa bandeira através das palavras liberdade, igualdade e humanidade.

Observa-se aí outro aspecto contraditório da cultura gaúcha: a valorização da liberdade e da igualdade confronta-se com o fato de 'boicotar' as prendas de chiripá.

Quanto às representações das jovens gaúchas como sujeitos possuidores de estudo e do papel de educar, de ser esposa e mãe, essas podem ser percebidas através da opinião de um dos entrevistados: "As gurias são enciclopédias do tradicionalismo, sabem cozinhar, encilhar cavalo e cevar um mate". De acordo com Dutra (2002,p. 119):

a prenda assim, assume as funções historicamente reservadas às mulheres: de esposa e mãe. Ela é a educadora, que transmite os valores pregados pelo Tradicionalismo para as gerações futuras, através das invernadas das danças, das palestras ministradas nas escolas, dos projetos assistencialistas realizados; ela que enfeita e arruma o salão para as festas do CTG; ela que recebe os convidados, estando sempre sorridente e enfeitada, tornado-se [sic] também o convite para eventos futuros.

Indo ao encontro dessa idéia, Walkerdine afirma que "a mulher é sistematicamente posicionada, governada e regulada de duas formas: como mãe que deve estimular a criança au- tônoma em desenvolvimento e como mão culpada por qualquer fracasso tanto da autonomia individual quanto do corpo social"' (1995, p. 213).

Outro texto, "A atuação social das prendas do MTG”, corrobora as características acima, ao afirmar que "ser prenda, além de representar a cultura tradicionalista, é conhecer a história, a geografia e o folclore do Estado para manter viva a tradição gaúcha”. Ainda, uma entrevistada diz que

a prenda é o estereótipo da cultura gaúcha e toda a preparação para sê-lo, em termos culturais, é uma experiência única de aperfeiçoamento pessoal. E quando a prenda ensina a história, a geografia, e o folclore do RS à comunidade, através dos trabalhos sociais, o aperfeiçoamento passa também para a população.

Assim, esses discursos reforçam o papel de educadora da prenda.

\section{SOBRE AS GAÚCHAS DESPORTISTAS...}

Do mesmo modo como as prendas buscam superar o preconceito em relação ao gênero feminino, também as jovens surfistas buscam isso através do esporte. A matéria "A prancha das gurias", de Deodor (2004), narra as mulheres como sujeitos determinados, que estão 'lutando' por seu espaço: "as mulheres saem da areia, entram no mar e disputam as ondas com os homens". Outra frase confirma essa afirmação: "as gurias, acostumadas a observar de longe as manobras radi- 
cais dos namorados, empunharam suas pranchas e também entraram no mar".

Os motivos que levam as gurias a esse tipo de atividade referem-se ao fato de "entrar em contato com a natureza, trabalhar a musculatura das pernas e dos braços, queimar calorias e calibrar o bronze", sendo esses "os valores agregados ao prazer maior de deslizar nas ondas". O texto ainda apresenta diversas entrevistas que reforçam essa idéia de cuidado com a aparência.

Essas mesmas questões são abordadas em "Gurias também amam”. O texto inicia produzindo discurso contra a discriminação: "Gurias não jogam nada. Quem diz isso merece no mínimo cartão amarelo". A fala de uma das jovens remete a esta idéia: "Dizem que somos homenzinhos, mas isso tudo é uma bobagem. As meninas que jogam são cada vez mais femininas". As características que remetem à feminilidade também são marcadas nesse texto na fala de uma das jovens, ao se referir à quadra como um vestiário feminino. Segundo ela, "A quadra vira um vestiário feminino. Falamos muita bobagem, é muito divertido". Sabat (2004) explica que "tagarelice e fofoca estão desde sempre relacionadas ao feminino, o que torna as mulheres agentes extra-oficiais de notícias e novidades, compartilhadas na cozinha, nos salões de chá, nas ruas, na igreja" (idem, p. 104).

Ser visto pelo outro, do sexo masculino, é uma das motivações para praticar o referido esporte. De acordo com o texto, "há um ponto em que profissionais e amadoras concordam. O futebol faz bem para a saúde e também para o ego. Não importa se os olhares vêm dos jogadores da quadra ao lado ou da arquibancada - paquera não é motivo para cartão vermelho".

A relação entre beleza e esporte também é observada em outro texto, "O tom discreto de Daiane", de Deodor (2003), o qual declara que a beleza da ginasta gaúcha é um dos motivos de receber títulos e medalhas: "Os olhos arregalados e o sorriso escancarado da ginasta gaúcha Daiane dos Santos, além de encantarem todo mundo, rendem títulos. O mais recente foi a medalha de ouro na prova de solo da Copa do Mundo de ginástica olímpica, na Alemanha". Assim, como observa Walkerdine, potencialidade é uma "característica que os/as professores/as descreviam como sendo própria dos garotos, mas [que] nunca era usada para descrever um garota" (WALKERDINE, 1995, p. 215). A autora acrescenta que "No caso das garotas, parecia se supor que aquilo que é visível na superfície é tudo o que existe, e que apenas os garotos têm profundezas ocultas" (Idem). Confirmando essa afirmação, está a seguinte frase: "Simpatia e graça, itens decisivos na modalidade em que Daiane é mestre, são reforçados por uma maquiagem caprichada". O texto segue mostrando, passo a passo, como Daiane, com a ajuda de uma maquiadora, faz sua maquiagem e, ao 
mesmo tempo, ensina também a leitora como fazê-la; em outras palavras, o texto remete à idéia de dependência, o que justifica a necessidade de ajuda.

Outro tema que o texto "A prancha das gurias" apresenta é a questão do namoro. Uma das gurias conta que aprendeu a surfar com seu namorado ("meu namorado é meu técnico", diz ela); outra expressa o desejo de ter a companhia do namorado no esporte ("quero que ele [namorado] compre uma prancha e complementa que só se ele surfar a gente vai poder ficar mais tempo juntos"); outra, ainda, diz que se interessou pelo esporte por causa de seu namorado, um surfista ("um dia começou a namorar um surfista fanático, que não desgrudava da prancha por nada. Como ela mesma diz, 'cansada de ficar dentro do carro, ouvindo rádio e comendo biscoito recheado, resolveu pegar a prancha e se aventurar", informa o texto). Aliás, a questão do relacionamento com o sexo oposto também é tratada nos textos sobre a prenda. Como já mencionado na análise acima, não são apenas os bons costumes, mas também "o fascínio da faixa e a dança [que] recrutam meninas. E os namorados potenciais também". Assim, observa-se que as jovens, ao participar de diversas atividades, parecem sempre estar em busca de um relacionamento, de um namorado ou marido.

No texto "Coisa de menina no mar", integrante da matéria "A prancha das gurias", são abordadas "coi- sas que são privilégios femininos", como escolher pranchas coloridas, com estampas de peixinhos, 'coraçõezinhos' ou com o desenho das Meninas Superpoderosas; ganhar um bronzeado, mas sem esquecer do filtro solar; usar sunguetes. Isso mostra como as jovens surfistas, apesar de praticarem um esporte predominantemente masculino, preservam algumas características ditas femininas, como o cuidado com a saúde, a beleza e a moda.

Há, contudo, um silenciamento no texto. Embora se trate de um esporte 'radical' - expressão que se refere a aventura, perigo, usada em revistas sobre surf dirigidas ao público masculino - não há, nesse texto, elementos que remetam a essa idéia. Desse modo, conclui-se que as garotas não se arriscam no mar, pois, afinal, não quebram regras, comportam-se bem, questão já mencionada anteriormente. Mesmo que haja no texto a palavra 'aventurar', esta está empregada no sentido de experimentar, de ousar (já que se trata de um esporte masculino): "cansada de ficar dentro do carro, ouvindo rádio e comendo biscoito recheado, resolveu pegar a prancha e se aventurar", narra o texto sobre uma das jovens.

\section{JOVENS MODELOS GAÚCHAS...}

Uma outra representação da jovem gaúcha ocorre no texto "As gaúchas são demais”, de Cunha (2000), para quem "o Rio Grande do Sul se 
tornou uma máquina de produzir top models", uma vez que a maioria delas são gaúchas. Várias causas são apontadas no que diz respeito a essa 'produção': "a primeira delas é que o padrão de beleza mais aceito hoje se encaixa como uma luva nas características físicas das mulheres dos pampas". Esse padrão de beleza diz respeito ao "estilo europeu, de mulheres com quase 1,80 metro de altura, pele clara e olhos azuis ou verdes". O texto também informa que "isso não falta no Rio Grande do Sul, Estado onde a população é formada por descendentes de imigrantes alemães, italianos e poloneses". Woodward (2000) constata que "a identidade é marcada pela diferença, mas parece que algumas diferenças [...] são vistas como mais importantes que outras, especialmente em lugares e em momentos particulares" (idem, p. 11). Assim, o 'sucesso' da beleza gaúcha advém das características européias, conseqüência da descendência étnica, fato que busca legitimar o status, a 'superioridade' das jovens gaúchas.

Contudo, há outras particularidades que justificam o 'sucesso' das modelos gaúchas, dentre as quais se destaca a determinação. "Geralmente vindas de famílias humildes e sem muitas perspectivas de crescimento na vida, elas se inspiram nos exemplos de sucesso e tomam a carreira de modelo com um norte para o sucesso profissional". Ainda, uma das entrevistadas acrescenta que "elas têm muita raça e mostram um profissio- nalismo acima da média".

Indo ao encontro dessas mesmas características está o texto "RS e SC mandam nas passarelas", de Feijó (2003), o qual informa sobre a experiência como modelo de diversas jovens gaúchas e catarinenses. Um dos entrevistados nessa matéria afirma que as agências preferem o sul porque os "sulistas têm o biótipo que agrada em cheio ao mercado nacional e internacional, resultado da mistura entre europeus e nativos e, por isso, tende a ser mais bonito e mais alto". Além disso, ele comenta que

o que também chama a atenção nas pessoas do Sul é o posicionamento social. As meninas têm uma maturidade precoce, um entendimento maior do significado do trabalho. As gaúchas, por exemplo, têm um charme natural e uma consciência corporal precoce. Acho que a questão étnica, cultural e até antropológica influência.

Para outro entrevistado, "esse sucesso também é resultado da vida mais saudável, boa alimentação e alta escolaridade do Sul".

Em suma, determinação, profissionalismo, bom comportamento (como ter uma vida saudável e uma boa alimentação) e um bom estudo estas duas últimas também presentes nas representações da prenda - são características que, associadas à questão étnica, justificam a 'superioridade' das jovens modelos gaúchas na profissão de modelo. 


\section{COSTURANDO AS IDÉIAS...}

As representações da jovem gaúcha, produzidas nos textos citados, condizem com o estudo realizado por Felipe (1999), a qual afirma que o sujeito feminino tem sido caracterizado de duas formas. Na primeira, características como cuidado, dedicação e maternagem são lidas como 'naturais' do gênero (como no papel da prenda). Na segunda, a mulher é sensual, faz ginástica, dietas e cuida da beleza (como as jovens que praticam esporte e as que são modelo). Ainda, essas jovens parecem estar sempre em busca de relacionamento com o sexo masculino em quaisquer espaços em que estejam, sendo, portanto, sujeitos heterossexuais. Também as características culturais gaúchas estão expressas nessas representações, o que as distingue de outras jovens brasileiras.

Além disso, parece que algumas jovens estão rompendo com o preconceito, pois estão 'lutando' pelo seu espaço no mundo do trabalho, no esporte, na tradição gaúcha, produzindo discursos que as representam como sujeitos capazes de pertencer e de se movimentar igualitariamente em espaços antes predominantemente masculinos.

Portanto, considerando as questões expostas neste texto, não devemos ignorar o fato de que muitas jovens, inclusive as de nossas escolas, estão, possivelmente, sendo continuamente inventadas, interpeladas, go- vernadas por esses discursos.

Devemos, pois, como educadores/ as,

desestabilizar as narrativas essencialistas, expondo seu caráter construído e, portanto, histórico. Precisamos desconfiar das afirmações universais e totalizantes, admitindo que o mundo é muito mais matizado e plurifacetado do que podemos supor. É preciso reconhecer que qualquer identidade se constrói nas arenas do mundo social e todas elas reivindicam e procuram assegurar espaços para existir. A riqueza está na diversidade, no plural que respeita o singular, que soma e não divide (COSTA, 2003).

Continuar a problematizar esses olhares produzidos na cultura sobre as jovens gaúchas é um dos caminhos necessários tanto para compreender que significados e discursos estão implicados nessas representações, como para desnaturalizar aquilo que é aceito como uma 'verdade'. Assim, aprenderemos a lidar com o singular e com o plural que fazem parte do mundo Pós-Moderno. Eis um dos nossos desafios como educadores/as.

\section{REFERÊNCIAS}

COSTA, M. Estudos culturais - para além das fronteiras disciplinares. In:

(Org.). Estudos culturais em educação: mídia, arquitetura, brinquedo, biologia, literatura, cinema... Porto Alegre: Editora da Universidade, 2000a.

Sujeitos e subjetividades nas tramas da linguagem e da cultura. In: CANDAU, V. M. (Org.). Cultura, lin- 
guagem e subjetividade no ensinar e aprender. Rio de janeiro: DP\&A, 2000b.

Diversidade,

multiculturalismo e diferença: uma conversa para professoras e professores. Texto em fase de publicação. 2003. Disponível em: <http://www.ufrgs.br/neccso/ frame10.html> Acessado em 03 mar. 2004

DUTRA, C. A prenda no imaginário tradicionalista. 2002, 141. Dissertação (História) - Pontifícia Universidade Católica do Rio Grande do Sul, Porto Alegre, 2002.

FELIPE, J. Entre tias e tiazinhas. In: HERON, L. (Org.). Século XXI: qual conhecimento? qual currículo? Petrópolis: Vozes, 1999.

HALL, S. A centralidade da cultura: notas sobre as revoluções culturais do nosso tempo. Educação \& Realidade, v. 22, n.2, jul./dez. 1997. Disponível em: $<$ http://www.ufrgs.br/neccso/ frame10.html $>$ Acessado em 03 mar. 2004.

Identidades culturais na pósmodernidade. Trad. Tomaz. T. da Silva e Guacira Louro. 2 ed. Rio de Janeiro: DP\&A, 1998.

KELLNER, D. Lendo imagens criticamente: em direção a uma pedagogia pós-moderna. In: SILVA, Tomaz T. (Org.). Alienígenas na sala de aula: uma introdução aos estudos culturais em educação. Petrópolis: Vozes, 1995.

REGUILLO, R. Las culturas juveniles, um campo de estúdio: breve agenda para la discusión. Revista Brasileira de Educação, Rio de Janeiro, n. 23, maio/ago., 2003.

SABAT, R. Só as bem quietinhas vão casar. In: Meyer, D; Soares, R (Org.). Corpo, gênero e sexualidade. Porto Alegre:
Editora Mediação, 2004.

SARLO, B. Cenas da vida pós-moderna: intelectuais, arte e vídeo-cultura na Argentina. Trad. Sérgio Alcides. Rio de Janeiro: Editora UFRJ, 1997.

SILVA, T. T. Documentos de identidade: uma introdução às teorias do currículo. Belo Horizonte: Autêntica, 2004.

SILVA, T. T. da. Teoria cultural e educação: um vocabulário crítico. Belo Horizonte: Cortez, 2000.

VEIGA-NETO, A. Michael Foucault e os Estudos Culturais. In: COSTA, M. V. (Org.). Estudos culturais em educação: mídia, arquitetura, brinquedo, biologia, literatura, cinema.... Porto Alegre: Editora da Universidade, 2000.

Olhares... In COSTA, M. V. (Org.). Caminhos investigativos: novos olhares na pesquisa em educação. Rio de Janeiro: DP\&A, 2002.

WALKERDINE, V. O raciocínio em tempos pós-modernos. Educação \& Realidade, Porto Alegre, v. 20, n. 2, jul/ dez. 1995.

WOODWARD, K. Identidade e diferença: uma introdução teórica e conceitual. I: Silva, T (Org.). Identidade e diferença: a perspectiva dos estudos culturais. Petrópolis, Vozes, 2000.

\section{TEXTOS ANALISADOS}

A ATUAÇÃO social das prendas do MTG. Jornal A Razão, Cultura Gaúcha, Santa Maria, 27de março de 2002.

CARAZINHO bicota prendas de chiripá. Jornal Correio do Povo, Porto Alegre, 21 de setembro de 2001 .

CUNHA, R. As gaúchas são demais. 
Revista Veja, São Paulo, 22 de março de 2000.

DEODOR, P. A prancha * Graduada em Letras pela Universidade Federal de Santa Maria. E-mail: sanarossi@yahoo.com.br

das gurias. Jornal Zero Hora, Revista ZH Donna, Porto Alegre, 04 de janeiro de 2004.

DEODOR, P. O tom discreto de Daiane. Jornal Zero Hora, Revista ZH Donna, Porto Alegre, 07 de dezembro de 2003.

FEIJÓ, M; PONTALTI, P; BELTRÃO T. RS e SC mandam nas passarelas. Jornal Zero Hora, Revista Donna ZH, Porto Alegre, 25 de maio de 2003.

GURIAS também amam. Jornal Zero Hora, Patrola, Porto Alegre, 16 de abril de 2004.

MOMENTO para reafirmar valores. Jornal Correio do Povo, Porto Alegre, 21 de setembro de 2001.

ROCHA, P. Mulher de tradição. Jornal Zero Hora, Revista ZH Donna, Porto Alegre, 22 de setembro de 2002.

Encaminhado em: 27/11/05

Aceito em: 28/03/06 